\section{Might stimulant drugs support moral agency in ADHD children?}

\author{
Steven Edward Hyman
}

\begin{abstract}
Stimulants have been shown to be safe and effective for reduction of the symptoms of attention deficit hyperactivity disorder. Despite much debate, however, there has been little empirical evidence as to whether stimulants affect authenticity and moral agency in children. Singh presents evidence that stimulants do not undercut children's' sense of self and increase their experience of agency. These findings are consistent with laboratory evidence that stimulant drugs in therapeutic doses improve cognitive control over thought and behavior.
\end{abstract}

A substantial medical literature demonstrates that stimulant treatment produces significant benefits for children with attention deficit hyperactivity disorder (ADHD). This literature also documents side effects, most commonly insomnia, appetite suppression and growth delay. Societal controversy notwithstanding, given well-diagnosed ADHD and appropriate dosage adjustment and side effect monitoring, clinical trials demonstrate that the benefits of stimulants clearly outweigh the risks. ${ }^{1}$ However, many questions about stimulant treatment of children are not addressed by published clinical trials, which perforce focus largely on symptom reduction. More complex life outcomes are often difficult to measure, decrease the statistical power of clinical trials, and would require trial durations so protracted as to prove unaffordable or potentially unethical for randomised subjects.

In the Journal of Medical Ethics, Singh ${ }^{2}$ uses an interview-based approach to address a significant question that is not well addressed in clinical trials: whether administration of stimulant drugs degrades the moral development of children. What are the possible concerns? Perhaps the ADHD diagnosis, or simply that fact that a physician has seen fit to prescribe stimulants, might undercut a child's sense of personal responsibility by suggesting a biological cause beyond his

Correspondence to Professor Steven E Hyman, Stanley Center, Broad Institute of Harvard and MIT, 7 Cambridge Center 5015, Cambridge, MA 02142, USA; seh@harvard.edu or her control. In concert, children treated with stimulants might believe that the resources needed for self-control are external, that is, for the most part residing in pill bottles, not in themselves. As a result, the stimulant-treated child might fail to develop fully as a responsible and effective moral agent. ${ }^{3}$ Less sophisticated critics of stimulant treatment do not recognise the more abstract question of whether children might internalise problematic symbols and signals as they ingest their tablets. Instead, they tend to see stimulants more concretely as pharmacological handcuffs. In their view, stimulants please misguided (or tyrannical) parents and teachers when they pharmacologically transmute children into well-behaved zombies.

The data and analysis provided by $\operatorname{Singh}^{2}$ represent a much needed empirical foray into a set of concerns generally discussed at a rather sterile theoretical level. The underlying data are derived from interviews with children drawn from approximately 150 families in the US and UK who were being treated with stimulants for ADHD. The children were asked about the effects of stimulant treatment on their sense of authenticity (a slippery term that deserves greater analysis) and moral agency. The majority did not detect a threat from stimulants to their authenticity: they retained their sense of self and their goals (albeit at the level of young children). Significantly, they noted that stimulants improved their capacity to meet normative expectations. The preponderant sense one gets from reading the interview excerpts and analysis is that the children do not experience stimulants as forcing conformity, but rather as providing them with greater ability to control themselves if they want to. Thus, stimulants provided the children with the generally welcome ability to master norms and tasks given to them. ${ }^{2}$

Of course, the children might have been deluded about the actual drug effects. Perhaps they are rendered so compliant that they fail to recognise their true plight as zombies. Several lines of evidence, external to the paper, favour the children's more empowered views of themselves reported by Singh. ${ }^{2}$ Perhaps the most elemental fact is that the effects of stimulants are transient. Only when individuals take the very high doses that characterise drug abuse, and do so for extended periods of time, do persistent negative effects emerge, including addiction and psychotic symptoms. In the therapeutic dose range, even long-acting formulations of stimulants tend to lose their effect by late afternoon unless a supplemental dose is given. Prior to their first morning dose, children are free of the stimulant effect and thus exhibit ADHD symptoms. In addition, as described by a subject in this study, ${ }^{2}$ children take occasional drug holidays with the agreement of their parents, for example, because they do not like taking pills, are troubled by side effects or enjoy their ADHD symptoms in certain safe settings. In short, the 'chemical handcuffs' view would require that the zombie state be remade anew each day. There is no evidence for such a bizarre scenario in the interviews ${ }^{2}$ nor is it plausible that children would fail to notice or, in many cases, rebel.

The more serious concern addressed by the interviews is whether the children interpret and internalise their diagnosis and treatment in ways that undercut their moral development. In my view, this concern hinges centrally on the degree to which stimulant treatment is experienced as an imposed cognitive or emotional state (even if the drug was freely taken) versus the degree to which it is experienced as providing a greater agency, that is, control over the child's own thought and behaviour. These alternatives should not be taken as a simple 'either/or' dichotomy because stimulants affect diverse aspects of arousal, motivation, emotion and cognition. In general, clinical observations and cognitive neuroscience corroborate the view expressed by interviewees that stimulants increase agency.

The core symptoms of ADHDinattention, impulsivity and hyperactivity -appear to result from abnormalities (perhaps reflecting developmental delay) in the function of neural circuits that undergird executive function ${ }^{4}$ (cognitive control of thought, emotion and behaviour). While excessive claims should not be made based on a still developing area of clinical neuroscience, there is convergent evidence from multiple experimental approaches on the effects of stimulants on executive function. Animal studies in the laboratory and human studies using imaging, pharmacology, and cognitive and behavioural testing demonstrate that stimulants act in prefrontal regions of the cerebral cortex to improve performance 
that is dependent on executive function. ${ }^{5}$ Interestingly, stimulants strengthen executive function independent of an ADHD diagnosis. While stimulants may produce greater relative improvement in those who are initially more impaired, ${ }^{6}$ their broad effectiveness contributes to the controversy over stimulant use, especially because current diagnostic standards for ADHD lack objective markers or good developmental benchmarking. ${ }^{7}$

This emerging picture suggests that by improving executive function, stimulants strengthen the ability of children with ADHD to ignore or suppress prepotent impulses or distracting external stimuli. Far from making children into zombies, appropriately prescribed stimulants would seem, as children in these interviews describe, to increase the reality and experience of agency. In the context of better self-control, it would seem far more propitious to teach children appropriate life lessons about personal responsibility.

\section{Competing interests None.}

Provenance and peer review Commissioned; internally peer reviewed.

\section{(6) \\ OPEN ACCESS}

Open Access This is an Open Access article distributed in accordance with the Creative Commons Attribution Non Commercial (CC BY-NC 3.0) license, which permits others to distribute, remix, adapt, build upon this work non-commercially, and license their derivative works on different terms, provided the original work is properly cited and the use is non-commercial. See: http://creativecommons.org/ licenses/by-nc/3.0/

To cite Hyman SE. J Med Ethics 2013;39:369-370.

Received 6 August 2012

Accepted 20 August 2012

Published Online First 21 September 2012

\section{(5) Linked}

- http://dx.doi.org/10.1136/medethics-2011-100224

- http://dx.doi.org/10.1136/medethics-2012-100879

- http://dx.doi.org/10.1136/medethics-2012-100961

- http://dx.doi.org/10.1136/medethics-2012-101283
I Med Ethics 2013:39:369-370

doi:10.1136/medethics-2012-100846

\section{REFERENCES}

1 MTA Cooperative Group. A 14-month randomized clinical trial of treatment strategies for ADHD. Arch Gen Psychiatry 1999;56:1073-86.

2 Singh I. Not robots: children's perspectives on authenticity, moral agency and stimulant drug treatments. J Med Ethics 2013:39:359-66.

3 President's Council on Bioethics. Beyond therapy: biotechnology and the pursuit of happiness. Washington DC: Dana Press, 2003.

4 Vaidya CJ, Bunge SA, Dudukovic NM, et al. Altered neural substrates of cognitive control in childhood ADHD: evidence form functional magnetic resonance imaging. Am J Psychiatry 2005;162:1605-13.

5 Swanson J, Baler RD, Volkow ND. Understanding the effects of stimulant medications on cognition in individuals with attention-deficit hyperactivity disorder: a decade of progress. Neuropsychopharmacol 2011;36:207-26

6 Mehta MA, Goodyer IM, Sahakian BJ. Methylphenidate improves working memory and set-shifting in $A D / H D$ : relationships to baseline memory capacity. I Child Psychol Psychiatry 2004;45:293-305.

7 Hyman SE. Cognitive enhancement: promises and perils. Neuron 2011;69:495-8. 